\title{
PERAN KELUARGA SEBAGAI PENGAWAS MENELAN OBAT ANTI TUBERKULOSIS PADA PASIEN TB PARU KAMBUH
}

Role Of Family As Supervisor Of Anti Tuberculosis Drugs In The Relapsed Pulmonary Tuberculosis Patients

\author{
Nahdah Shofi Zhafirah, Lingling Marinda Palupi* \\ Poltekkes Kemenkes Malang \\ *)Email: linglingmarinda@gmail.com
}

\begin{abstract}
Genesis tuberculosis relapse is fairly typical of those with pulmonary tuberculosis. The onset of these relapse can cause new problems because it increases the likelihood of 'resistance from anti-tuberculosis drugs returning with stronger germs and making it more difficult to treat, medical expenses were higher and treatment success rates are lower. So the study aims to describe the role of the family in supervising the treatment of pulmonary tuberculosis patients with relapse cases from December 16th, 2019 to December 23, 2019. The study used interviews and observation methods on the two supervising families who swallowed pulmonary TB patients medications by cases of relapses. The results of this study indicate that the family is optimal in playing a role as a motivator for pulmonary tuberculosis patients and as a supervisor for swallowing drugs, the family has not been optimal in carrying out its role in reminding the sputum re-examination of pulmonary tuberculosis patients with relapse cases and as a companion providing education by health workers about pulmonary tuberculosis with relapse cases. The family may play the role of PMO that watches those with lung TB take the drug regularly until the end of treatment, thus fulfilling the patient's adherence to his obedience to taking the drugs and therapy that are given goes well.
\end{abstract}

Keywords : Supervisor Of Anti Tuberculosis Drugs, Family Roles, Pulmonary Tuberculosis

\section{ABSTRAK}

Kejadian TB kambuh/relaps adalah kejadian yang cukup sering pada penderita TB paru. Adanya kejadian relaps ini dapat menimbulkan masalah baru karena meningkatkan kemungkinan resistensi obat anti tuberkulosis dapat kembali dengan kuman yang lebih kuat sehingga lebih sulit diobati, biaya pengobatan lebih mahal dan tingkat keberhasilan pengobatan lebih rendah. Sehingga penelitian ini bertujuan untuk mendeskripsikan peran keluarga dalam mengawasi pengobatan pasien TB Paru dengan kasus kambuh dari tanggal 16 Desember 2019 sampai 23 Desember 2019. Penelitian ini menggunakan metode wawancara dan observasi pada 2 keluarga yang menjadi pengawas menelan obat pasien TB Paru dengan kasus kambuh. Hasil penelitian ini menunjukkan keluarga berperan dengan baik sebagai motivator pasien TB Paru, keluarga belum optimal dalam menjalankan perannya mengingatkan pemeriksaan ulang dahak pasien TB Paru, keluarga berperan baik sebagai pengawas menelan obat dan sebagai pendamping pemberian edukasi tentang TB Paru dengan kasus kambuh. Keluarga bisa berperan sebagai PMO yang mengawasi penderita TB paru agar menelan obat secara teratur sampai selesai pengobatan, sehingga terwujud kepatuhan penderita TB paru terhadap kepatuhannya dalam menelan obat dan terapi yang diberikan berjalan dengan baik.

Kata kunci : PMO, Peran keluarga, TB Paru

\section{PENDAHULUAN}

Penularan bakteri mycobacterium tuberculosis terjadi ketika pasien tuberkulosis (TB) paru mengalami batuk atau bersin sehingga bakteri tersebut tersebar ke udara dalam bentuk percikan dahak atau droplet yang dikeluarkan penderita TB paru. Penderita tuberkulosis yang sembuh dapat kambuh lagi karena adanya kuman endogen (Kemenkes RI, 2016). Adanya kejadian relaps dapat menimbulkan masalah baru karena meningkatkan kemungkinan resistensi obat anti tuberkulosis. Bahaya resistensi obat adalah penyakit TB dapat kembali dengan kuman yang lebih kuat sehingga lebih sulit diobati, biaya pengobatan lebih mahal dan tingkat keberhasilan pengobatan lebih rendah (Alfian, 2005 dalam Diah, Pad, dkk, 2016).

TB paru dengan kasus kambuh terjadi di beberapa negara di dunia antara lain di India dengan jumlah kasus relaps sebanyak 106.463 kasus, Korea dengan jumlah kasus relaps sebanyak 6.701 kasus, Myanmar dengan jumlah kasus relaps sebanyak 4.558 kasus, dan Bangladesh dengan jumlah kasus relaps sebanyak 3.065 kasus (WHO, 2008). Jumlah 
kasus pengobatan ulang di Indonesia adalah sebanyak 8.542 kasus, dan 70\% diantaranya merupakan kasus relaps (Depkes RI, 2014). Prevalensi TB paru berdasarkan diagnosis dokter menurut kabupaten/kota Provinsi Jawa Timur 20132018 mengalami peningkatan yaitu $0,2 \%$ pada tahun 2013 dan meningkat menjadi $0,29 \%$ pada tahun 2018 (Riskesdas, 2018). Berdasarkan data Dinas Kesehatan (Dinkes) Kota Malang, pada tahun 2016 penderita TB sebanyak 1.851 jiwa. Jumlah ini meningkat dibandingkan 2015 yang tercatat sebanyak 1.123 jiwa. Selama tahun 2016, terdapat 494 pasien penderita TB paru mendapat pengobatan. Mereka adalah penderita yang sakit sejak tahun 2015. Sesuai jumlah tersebut, penderita yang dinyatakan sembuh pada tahun 2016 sebanyak $67 \%$ atau sebanyak 331 penderita.

Tidak semua penderita tersebut menyelesaikan pengobatan dan dinyatakan pengobatan lengkap. Hal ini menunjukkan kesadaran untuk meminum obat sesuai petunjuk tenaga medis masih rendah, walaupun terjadi peningkatan angka pengobatan lengkap (Profil Kesehatan Kota Malang, 2015)[5]. Peranan keluarga sangat dibutuhkan dalam proses pengobatan penderita TB paru. Secara pribadi keluarga merupakan faktor utama dalam penyembuhan pasien. Keluarga bisa berperan sebagai Pengawas Menelan Obat (PMO) yang mengawasi penderita TB paru agar menelan obat secara teratur sampai selesai pengobatan, sehingga terwujud kepatuhan penderita TB paru terhadap kepatuhannya dalam menelan obat sehingga terapi yang diberikan berjalan dengan baik (Handhayani, 2011 dalam Istianna, Arlina, dkk, 2016).

Salah satu penyebab ketidakberhasilan pengobatan adalah karena ketidakpatuhan berobat penderita masih tinggi. Masalah kepatuhan pasien dalam menyelesaikan program pengobatan merupakan prioritas paling penting. Ketidakmampuan pasien menyelesaikan regimen self-administered, akan menyebabkan terjadinya kegagalan pengobatan, kemungkinan kambuh penyakitnya, resisten terhadap obat, dan akan terus-menerus mentransmisikan infeksi (Vijay, Balasangameswara, Jagannatha, Saroja, \& Kumar, 2003 dalam Murtiwi, 2006). Pengawasan terhadap adanya efek samping pada setiap pengobatan perlu dilakukan, karena hampir semua obat anti tuberkulosis mempunyai efek samping (IImu Penyakit Paru, 2010). Peran keluarga sebagai pengawas menelan obat diharapkan mampu memberikan dukungan kepada penderita agar semangat dalam mengikuti pengobatan sampai tuntas. Keluarga sebagai pengawas menelan obat pasien TB diharapkan mampu memberikan motivasi dan edukasi yang mudah diterapkan oleh pasien dan keluarga tersebut, sehingga tidak terjadi putus obat dan bakteri tidak kebal terhadap obat. Keluarga sebagai pengawas minum obat harus terlebih dahulu diberikan edukasi oleh tenaga kesehatan, agar memahami penyakit TB paru dan mampu merawat pasien dengan baik serta menjadi pengawas menelan obat yang tepat. Berdasarkan latar belakang di atas, peneliti tertarik untuk melakukan penelitian tentang hal ini di wilayah kerja Puskesmas Poncokusumo.

\section{METODE}

Desain penelitian ini yaitu penelitian deskriptif kualitatif yang menggunakan metode wawancara dan observasi pada 2 keluarga sebagai pengawas menelan obat pasien TB Paru dengan kasus kambuh. Tempat penelitian pada 2 keluarga tersebut berada di Desa Dawuhan dan Desa Poncokusumo, dimana keduanya merupakan wilayah kerja dari Puskesmas Poncokusumo. Pengambilan data dilaksanakan dari tanggal 16 Desember 2019 sampai 23 Desember 2019.

\section{Jumlah dan cara pengambilan subjek}

Subjek dalam penelitian ini adalah 2 keluarga yang mengantarkan pasien TB paru dengan kasus kambuh berobat di Puskesmas Poncokusumo dengan kriteria tinggal serumah dengan pasien, keluarga yang terus mendampingi dan berinteraksi setiap hari, serta dapat membaca dan menulis. Pemilihan subjek penelitian dilakukan di Puskesmas Poncokusumo dengan cara meminta data warga yang sakit tuberkulosis paru kepada penanggung jawab Poli TB Puskesmas Poncokusumo. Kemudian peneliti memilahnya sesuai kriteria yang sudah ditentukan, diutamakan keluarga dengan pasien penderita TB paru dengan kasus kambuh. Peneliti terlebih dahulu membina hubungan saling percaya dengan calon responden dan menjelaskan maksud dan tujuan penelitian. Kemudian menjelaskan isi dari informed consent, jika calon responden setuju maka diminta untuk memberikan tanda tangan di lembar informed consent. Kemudian peneliti menjelaskan bahwa akan mewawancarai dan mengobservasi subjek dalam menjalankan perannya sebagai pengawas menelan obat selama 8 hari, dan meminta ijin untuk adanya dokumentasi dalam penelitian.

\section{HASIL}

Subjek penelitian 1 usia 30 tahun beragama Islam, bersuku Jawa, pendidikan terakhir SD/MI. Subjek tinggal bersama suami dan anaknya, yang menderita TB paru adalah suaminya berusia 37 tahun dengan pengobatan yang sudah berjalan selama 7 bulan. Pekerjaan yang dilakukan subjek adalah membuat kue yang setiap harinya dijual oleh suaminya setelah pulang dari sawah. Subjek merasa khawatir saat mengetahui suaminya sakit dan tidak pernah berhenti untuk terus menasehati suaminya 
agar rutin melakukan pengobatan. Lama-kelamaan subjek sudah jarang mengawasi pengobatan suaminya, karena kali ini merupakan pengobatan ulang (kasus kambuh). Kasus tersebut kambuh selang 3 tahun setelah pengobatan pertama.

Subjek penelitian 2 umur 82 tahun beragama Islam, bersuku Jawa, pendidikan terakhir SD/MI. Subjek tinggal bersama anaknya berusia 31 tahun yang menderita TB paru. Pekerjaan yang dilakukan subjek adalah menjual makanan di kantin sekolah. Setiap pagi subjek selalu mengawasi pengobatan putranya yang sudah berjalan selama 3 bulan. Responden merasa khawatir saat putranya terlihat makin kurus dan lemah. Namun, saat ini kondisi fisik putranya sudah membaik dan tidak kurus lagi, karena pengobatan kali ini merupakan pengobatan ulang (kasus kambuh). Kasus tersebut kambuh selang 4 tahun setelah pengobatan pertama.

\section{PEMBAHASAN}

Dari kedua keluarga didapatkan selalu memberikan motivasi kepada penderita agar tidak bosan minum obat dan memiliki harapan agar penderita cepat sembuh. Motivasi yang diberikan keluarga sangat berpengaruh pada semangat penderita dalam menjalankan pengobatan. Motivasi yang dapat memberikan semangat pada kedua penderita adalah dengan mengingatkannya bahwa memiliki keluarga yang menyayangi dan keluarga ingin penderita cepat sembuh. Walaupun kedua penderita TB Paru pekerjaannya sering di luar rumah dan terpapar debu sehingga memungkinkan akan memperberat kondisi kesehatannya.

Penelitian Wahyuni (2013) mengungkapkan aktivitas yang rentan terpapar oleh asap dan debu serta lamanya paparan akan mempengaruhi saluran pernapasan sehingga akan lebih mudah terpapar kembali oleh kuman TB. Aktivitas yang tinggi dan jenis pekerjaan yang tergolong pekerjaan berat mempengaruhi terjadinya kekambuhan TB paru karena dapat menurunkan daya tahan tubuh pasien (Batista, J. d., Albuquerque, M. d., Ximenes, R. A., \& Rodrigues, L. C. (2008).

Keluarga sebagai pengawas menelan obat berperan memberikan motivasi atau dorongan agar pasien termotivasi untuk menjalani pengobatan sesuai aturan hingga sembuh. Bentuk peran yang diberikan adalah berupa dukungan moral dan harapan kesembuhan bagi penderita (Wiwit, Febrina, 2018). Dukungan dari orang-orang terdekat, salah satunya keluarga sangat diperlukan dalam pengobatan TB Paru, karena dukungan keluarga adalah dukungan sosial paling utama yang dibutuhkan pasien. Dukungan keluarga memegang peranan penting bagi pasien TB Paru dalam menjalani pengobatan yang termotivasi untuk sembuh (Bumbunan, Fatmawati, dkk, 2017). Semakin baik dukungan keluarga yang diberikan kepada penderita TB, maka semakin tinggi kepatuhan minum obat pada penderita tersebut $(\mathrm{Ni}$ Made, lyone E. T. dkk, 2015).

Peran keluarga dalam pemeriksaan ulang dahak pasien TB Paru pada kedua keluarga kurang optimal dilakukan, karena kedua penderita tidak pernah mengingatkan hanya memberitahu saja saat akan pemeriksaan ulang dahak. Keduanya rutin melakukan pemeriksaan dahak sesuai permintaan puskesmas tanpa diingatkan keluarganya. Kedua penderita memiliki kesadaran terhadap pentingnya pemeriksaan dahak untuk perkembangan pengobatannya. Pemeriksaan ulang sputum sangat penting dilakukan untuk mengetahui ada tidaknya bakteri untuk selanjutnya dapat dipastikan bahwa penderita sudah sembuh.

Pemantauan kemajuan hasil pengobatan pada orang dewasa dilaksanakan dengan pemeriksaan ulang dahak secara mikroskopis. Pada pasien paru BTA positif dengan pengobatan ulang kategori 2 pemeriksaan ulang dahak dilakukan pada akhir intensif, bulan ke-5 pengobatan, dan pada akhir pengobatan (Pedoman Nasional Pengendalian Tuberkulosis, 2011). Peran keluarga dalam mengingatkan pasien untuk melakukan pemeriksaan ulang dahak sangat diperlukan, karena hal tersebut merupakan salah satu peran keluarga sebagai pengawas menelan obat. Pemeriksaan ulang sputum ini dilakukan karena dapat menentukan sejauh mana keberhasilan pengobatan bagi pasien TB Paru (Wiwit, Febrina, 2018).

Peran keluarga sebagai pengawas menelan obat sangatlah dibutuhkan dalam keberhasilan pengobatan pasien TB Paru. Dari kedua responden sudah menjalankan perannya dengan baik dibuktikan dengan responden 1 yang melakukan pengawasan pada 1 minggu pertama awal pengobatan dan responden 2 melakukan pengawasan selama 3 minggu awal pengobatan TB Paru dengan kasus kambuh.

Peran keluarga sebagai pengawas menelan obat sangat baik karena dapat mengurangi resiko kegagalan dalam pengobatan dan membantu meningkatkan semangat dan kepercayaan diri penderita untuk dapat sembuh (Juwita, 2009). Menurut Efendi dan Makhfdli (2013) kemampuan keluarga dalam memberikan perawatan kesehatan mempengaruhi status kesehatan keluarga. Hal ini menunjukkan bahwa dalam menjalankan peran sebagai pengawas menelan obat membutuhkan suatu kemampuan dan komitmen yang sungguh sehingga perawatan anggota keluarga yang menyandang TBC dapat memperoleh keberhasilan perawatan.

Peran keluarga sebagai edukator belum 
optimal dijalankan, karena keduanya tidak pernah ikut penderita TB Paru kontrol dan mengambil obat ke Puskesmas Poncokusumo. Namun, hal tersebut tidak menjadi penghambat untuk kedua responden dalam memberikan edukasi untuk tidak merokok hingga saat ini akhirnya mereka berhenti merokok. Seperti yang tertulis pada The Journal of Medical Research (2019) bahwa perokok pada penderita tuberkulosis kambuhan beresiko tinggi kematian. Depkes RI (2008) dalam program penanggulangan TB Paru, penyuluhan langsung perorangan sangatlah penting dilakukan untuk menentukan keberhasilan pengobatan. Kurangnya penyuluhan kesehatan tentang TB Paru serta kekambuhan TB Paru dari petugas kesehatan menyebabkan kurangnya informasi mengenai penyakit TB paru. Pengetahuan yang rendah akan TB Paru menyebabkan kurangnya pengertian pengetahuan penderita terhadap penyakit serta bahaya dari penyakit tersebut (Yesika, 2016).
Penelitian ini menunjukkan keluarga berperan dengan baik sebagai motivator pasien TB Paru kasus kambuh, keluarga belum optimal dalam menjalankan perannya mengingatkan pemeriksaan ulang dahak pasien TB Paru kasus kambuh, keluarga berperan baik sebagai pengawas menelan obat dan sebagai pendamping pemberian edukasi tentang TB Paru dengan kasus kambuh.

\section{SARAN}

Diharapkan bagi petugas kesehatan mampu memberikan pelayanan yang terbaik serta memberikan informasi yang berhubungan tentang penyakit TB Paru kepada keluarga dan pasien TB Paru. Bagi keluarga pasien diharapkan lebih meningkatkan pengawasan pengobatan pasien TB Paru dan menjalankan peran keluarga sebagai pengawas menelan obat dengan selalu mengikuti pasien TB paru untuk kontrol ke puskesmas serta terus memberikan edukasi dengan tepat.

\section{KESIMPULAN}

\section{DAFTAR PUSTAKA}

Batista, J. d., Albuquerque, M. d., Ximenes, R. A., \& Rodrigues, L. C. (2008). Smoking increases the risk of relapse after successful tuberculosis treatment. International Journal of Epidemiology , 841-851

Bumbunan, Fatmawati, dkk. 2017. Peran Pengawas Menelan Obat (Pmo) Terhadap Pengobatan Penderita tuberkulosa Diwilayah Kerja Unitpengobatan Penyakit Paru-Paru (Up4) Pontianak .Jurnal. Universitas Tanjungpura Pontianak

Departemen Kesehatan Republik Indonesia.Pedoman Nasional Penanggulangan Tuberkulosis. Jakarta: 2011

Departemen Kesehatan Republik Indonesia.Pedoman Nasional Penanggulangan Tuberkulosis. Jakarta: 2008.

Diah, Pad, dkk. 2016. Penatalaksanaan Tuberkulosis Paru Kasus Kambuh Pada Wanita Usia 32 Tahun Di Wilayah Kerja Rajabasa. Jurnal. Fakultas Kedokteran Universitas Lampung.

Dinas Kesehatan Kota Malang.Profil Kesehatan Kota Malang tahun 2015. Malang : Dinas Kesehatan; 2016

Efendi, F., Makhfudli. 2013. Keperawatan Kesehatan Komunitas, Teori dan Praktik Dalam Keperawatan. Jakarta : Salemba Medika

Istianna, Arlina, dkk. 2016. Peran Keluarga Pada Kepatuhan Minum Obat Penderita TB Di Kawedanan Pedan Klaten. Jurnal. Stikes Muhammadiyah Klaten.

Juwita, 2009. Hubungan Kinerja Pengawas Minum Obat (PMO) dengan keteraturan berobat pasien TB Paru Strategi DOTS di RSUD Dr. Moewardi Surakarta.

Murtiwi, 2006. Keberadaan Pengawas Minum Obat (PMO) Pasien Tuberkulosis Paru Di Indonesia. Jurnal Keperawatan Indonesia, Volume 10, No.1, Maret 2006:11-15

Ni Made, lyone, dkk., 2015. Pengaruh Dukungan Keluarga Terhadap Kepatuhan Minum Obat Pada Penderita Tuberkulosis Di Puskesmas Motoboi Kecil Kota Mobagu.. Universitas Sam Ratulangi Manado

Pusat Data dan Informasi Kementrian Kesehatan RI, 2014

Pusat Data dan Informasi Kementrian Kesehatan RI, 2016 
Tabrani, 2010. IImu Penyakit Paru. Jakarta : Trans Info Media

The Journal of Medical Research, 2019. Epidemiological Profile Of Pulmonary Tuberculosis Relapse Cases In The City Of Butembo East Of The Democratic Republic Of Congo. Journal.University of Abomey Calavi,Republic of Benin and Senior lecturer in the Faculty of Medicine of The Catholic University of Graben DRC

Wahyuni, Y., Saad, A., \& Suyanto. (2013). Analisis Kualitatif Kejadian Relaps Tuberkulosis Paru di Puskesmas Sidomulyo Pekanbaru Tahun 2011-2012. IImu Kesehatan Masyarakat Kedokteran Komunitas Fakultas Kedokteran Universitas Riau

WHO Global Tuberculosis Control (2012)

Wiwit, Febrina. 2018. Analisis Peran Keluarga Sebagai Pengawas Menelan Obat Pasien TB Paru. Jurnal. Stikes Fort De Kock Bukittinggi

World Health Organization, 2008

Yesika, 2016. Studi Fenomenologi : Faktor Terjadinya Kekambuhan Tuberkulosis Paru di Wilayah Kecamatan Pontianak Utara tahun 2015. Naskah Publikasi. Universitas Tanjungpura Pontianak 